Letter to the Editor

\title{
Acute crocodile tear syndrome without antecedant facial nerve palsy
}

\author{
Chi Yun Doreen Ho MBBS ${ }^{1}$ and Thomas G Hardy FRANZCO ${ }^{1,2}$
}

Department of Ophthalmology, Royal Melbourne Hospital, Parkville, VIC, Australia ${ }^{1}$ Department of Surgery, Royal Melbourne Hospital University of Melbourne, Parkville, Victoria, Australia ${ }^{2}$

Correspondence: Thomas G Hardy, Department of Ophthalmology, The Royal Melbourne Hospital, 300 Grattan St, Parkville, VIC 3050, Australia

Email: $\quad$ hardy_tg@bigpond.net.au

Received 28 November 2017; accepted 28 January 2018

Conflict of interest: None

Funding sources: None

This is the author manuscript accepted for publication and has undergone full peer review but has not been through the copyediting, typesetting, pagination and proofreading process, which may lead to differences between this version and the Version of Record. Please cite this article as doi: $10.1111 /$ ceo.13173

This article is protected by copyright. All rights reserved. 
Crocodile tear syndrome (CTS) is a rare symptom characterized by excessive unilateral tearing occurring with gustatory stimuli known to develop as a sequel of facial nerve involvement as evident by facial palsy on the affected side.(1) CTS may more rarely occur without antecedent facial palsy with only four cases described in English literature.(2)

We describe the case of a 47-year-old male with an unremarkable past medical and ocular history whom sustained a motor vehicle accident in 1995 resulting in partial amputation of his left pinna that required partial pinnectomy in 2000. In October 2013 he underwent residual left pinnectomy and implantation of three osseointegrated implants for prosthetic ear reconstruction. These were uncovered in a second stage procedure in July 2014. Three weeks after the second stage procedure, he described new left-sided symptoms of otalgia, hearing loss, and lacrimation stimulated only when eating. At no stage was there any history or clinical evidence of facial weakness.

The patient was referred to the Ophthalmology unit in April 2015. On examination, the patient had best corrected visual acuity of 6/6 in each eye. Colour vision, visual fields and pupil examination were normal. Extraocular movements were full with no nystagmus or diplopia in any position of gaze. There was no ptosis. Corneal and facial sensation were equal and normal bilaterally with normal, symmetrical facial movement. Specifically, there was no evidence of any facial weakness nor synkinesis on the left side. Stimulation of salivation resulted in tearing of the left eye. The rest of the examination including slit-lamp biomicroscopy, intraocular pressure 
measurements, and fundoscopy revealed no abnormality. Investigations on high resolution computed tomography through temporal bones showed no evidence of facial fracture and the osseous implants were in satisfactory position.

A diagnosis of CTS was made and 10 IU of botulinum toxin A was injected transcutaneously into the left lacrimal gland just inferior to the orbital rim and provided symptomatic relief for approximately 6 -months post treatment. This was complicated by left-sided ptosis but resolved 6 weeks after onset. Treatment has been repeated on two further occasions at six month intervals without complication.

Our case is unique in that our patient did not experience facial palsy at any time in association with his acquired crocodile tears and that the onset of development was of a short duration from his second stage procedure. This is rare in literature and to the best of our knowledge, only a handful of other cases have demonstrated CTS occurring without facial palsy but have all occurred months after the initial insult. One case by Klein et a(3) reported that CTS was the only evidence of facial nerve dysfunction as a result of a slow growing meningioma but resulted from selective damage to the superior salivatory nucleus, as neuroimaging indicated the lesion involving pontine tegmentum.(3) Boyer et al(1) described two cases that developed CTS after resection of the greater superficial petrosal nerve for intractable headaches. They suggested that this was due to regenerated autonomic nerve fibres and found that sectioning of the glossopharyngeal nerve relieved CTS hypothesising that this nerve was also crucial to the development of the condition.(1) GoldingWood(2) described a case of resection of greater superficial petrosal nerve with the subsequent development of CTS years later that was relieved by resection of the tympanic branch of the glossopharyngeal nerve. He proposed that collateral axonal sprouting occurred from the glossopharyngeal preganglionic salivary nerves, where the tympanic branch joins the greater superficial petrosal nerve and that these 
misdirected salivary branches aberrantly re-innervate the sphenopalatine ganglion and thus stimulate the lacrimal gland which differs from pathogenesis of CTS with antecedent facial nerve palsy (see Figure 1).(2)

In our patient, we postulate that CTS involved some form of ephaptic transmission or increased excitability of brainstem interneurons given its acute development. Alternatively, the development of his syndrome may have followed his operation 9 months earlier in October 2013, which fits with the time frame for aberrant regeneration. Furthermore, we support the theory of involvement of the glossopharyngeal nerve in the development of CTS and in this case, at the origin of the middle ear where tympanic branch divides into tympanic plexus which potentially explains the patients' CTS without any evidence of facial nerve palsy.

Previous treatment options for CTS have included intraorbital injection of alcohol or cocaine to destroy postganglionic fibres of the sphenopalatine ganglion, subtotal dacryoadenectomy and sectioning of the glossopharyngeal and facial nerves at various levels. $(1,2,4)$ However, these have been variable in their outcomes and in some, resulted in total ablation of lacrimal secretion which could ultimately threaten sight. More recent studies have shown the effective and safe use of botulinum toxin type A.(5) We have found this treatment option effective with minimal complications in our patient with CTS.

\section{REFERENCES}

1. Boyer F, Gardner W. Paroxysmal lacrimation (syndrome of crocodile tears) and its surgical treatment: relation to auriculotemporal syndrome. Arch Neurol Psychiat. 1949;61:56-64.

2. Golding-Wood P. Crocodile tears. Br Med J. 1963;8(1):1518-21. 
3. Klein $A$, Miller $\mathrm{N}$. Isolated acquired primary gusto-lacrimal reflex from a brainstem glioma. Neurology.81:1877-8.

4. Axelsson A, Laage-Hellman J. The Gusto-Lachrymal Reflex: The Syndrome of Crocodile Tears. Acta Oto-Laryngologica. 1962;54:239-54.

5. Montoya F, Riddell C, Caesar R, Hague S. Treatment of gustatory

hyperlacrimation (crocodile tears) with injection of botulinum toxin into the lacrimal gland. Eye. 2002;16:705-9. 


\section{FIGURE LEGEND}

Figure 1: Schematic diagram of new gustolacrimal reflex arc following nerve injury at two different sites. A. Crocodile tear syndrome with antecedant facial nerve palsy. Misdirection of regenerating salivary fibres destined for the salivary glands become secretory fibres to the lacrimal gland thus establishing a new reflex arc, causing ipsilateral tearing while the patient is eating. If the lesion is in the facial nerve proximal to or involving the geniculate ganglion (explaining its association with an antecedent facial nerve palsy) where the lacrimal and salivary fibres run together, abnormal regeneration of gustatory fibers occurs through the greater superficial petrosal nerve to reach the lacrimal gland (instead of the normal pathway through the chorda tympani to the submaxillary gland). B. Crocodile tear syndrome without antecedent facial nerve palsy. Misdirection of regenerating salivary fibres of glossopharyngeal nerve where tympanic branch divides into tympanic plexus to aberrantly re-innervate the sphenopalatine ganglion and thus stimulate the lacrimal gland. 

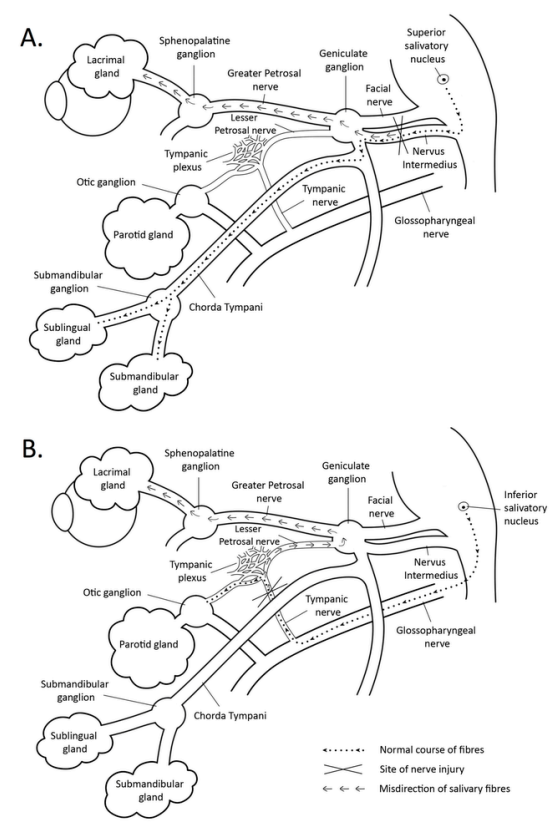

CE0-17-11-1060 figure 1.tif

This article is protected by copyright. All rights reserved. 


\section{University Library}

\section{- M M I E E R VA A gateway to Melbourne's research publications}

Minerva Access is the Institutional Repository of The University of Melbourne

Author/s:

Ho, CYD;Hardy, TG

Title:

Acute crocodile tear syndrome without antecedent facial nerve palsy

Date:

2018-09-01

Citation:

Ho, C. Y. D. \& Hardy, T. G. (2018). Acute crocodile tear syndrome without antecedent facial nerve palsy. CLINICAL AND EXPERIMENTAL OPHTHALMOLOGY, 46 (7), pp.809-811. https://doi.org/10.1111/ceo.13173.

Persistent Link:

http://hdl.handle.net/11343/283700 